\title{
Immersive virtual reality as a tool to learn problem-solving skills
}

\author{
Paola Araiza-Alba ${ }^{1 *}$ \\ paraiza@swin.edu.au
}

Therese Keane ${ }^{1}$

tkeane@swin.edu.au

Won Sun Chen ${ }^{1}$

wchen@swin.edu.au

Jordy Kaufman ${ }^{1}$

jkaufman@swin.edu.au

${ }^{1}$ Swinburne University of Technology, PO Box 218, Hawthorn, Victoria, Australia

*Corresponding Author: Paola Araiza-Alba, paraiza@swin.edu.au, Phone: +61392148822 


\begin{abstract}
Immersive virtual reality (IVR) technology has demonstrated positive educational outcomes related to its use and is gaining traction in educational and training settings; IVR is expected to have widespread adoption within the classroom in the upcoming years. However, the educational potential of IVR has not been thoroughly investigated, especially as a tool for problem-solving skills. Therefore, this study was designed to answer the following questions: (1) Is IVR a useful tool to learn and practice problem-solving skills? More specifically, do children using IVR solve a game better than those using a tablet application or a board game? (2) Does IVR provide a more engaging experience for children to practice problem-solving skills than on a tablet or a board game? (3) Do problem-solving skills learned with IVR technology transfer to real-life (physical game)? Children $(n=120)$ aged $7-9.9$ years were randomly assigned to a problem-solving game in one of three conditions: board game, tablet, or IVR. The results showed that, overall, the percentage of children who completed the problem-solving game was higher in the IVR condition (77.5\%), compared with those in the tablet $(32.5 \%)$ or board game $(30 \%)$ conditions. We also found that the interest and enjoyment scores of participants using IVR were significantly higher than participants in the other two conditions, and that the children in the IVR condition were able to learn how to solve the problem and transfer their learning to the physical game. IVR is a technology capable of engaging interest and motivating the user, as well as having the potential to assist in cognitive processing and knowledge transfer.
\end{abstract}

\title{
Key words
}

Augmented and virtual reality, 21st century abilities, problem-solving skills, elementary education, games

\subsection{Introduction}


In 2012, the National Research Council (USA) defined 21st century skills as fundamental to the learning process (Pellegrino \& Hilton, 2012); these skills were divided into three domains of competency: interpersonal, intrapersonal, and cognitive. The cognitive domain includes critical thinking, creativity, executive functioning, and problem-solving skills (Gretter \& Yadav, 2016; Papanastasiou, Drigas, Skianis, Lytras, \& Papanastasiou, 2018). Problem-solving is the basis for executive function skills (Luria, 1966), and it is defined as a process that requires the ability to define and identify a problem, seek alternative solutions, and implement the best possible solution in relatively new situations (Yu, Fan, \& Lin, 2015).

In the initial stage of learning problem-solving and goal-directed behaviour, working memory is crucial (Serino et al., 2006); thus, acquiring the first building blocks of these skills is one of the most critical and challenging tasks of the early and middle childhood years (Brocki \& Bohlin, 2004). Between the ages of 7 and 9 years old, working memory, attention, and flexibility significantly increase; therefore, middle childhood is an important stage where these skills build further and become essential for healthy child development. Moreover, developing flexible, transferable problem-solving skills is vital in a contemporary educational system (Kalyuga, Renkl, \& Paas, 2010) because they have a positive influence on instilling early literacy and numeracy proficiency.

Technology is seen as an instrument to enrich learning experiences that foster the development of 21 st century skills 2016; Sanabria \& ArámburoLizárraga, 2017) [Authors (2016). To be added following double blind review], and computer environments that contain cognitive tools or scaffolds to support students' learning and constructivist principles could be used as a medium to learn those skills (Crockett, Jukes, \& Churches, 2011).

\subsection{Virtual reality}


Virtual reality (VR) is defined as a three-dimensional (3D), computer-generated environment that simulates or replicates aspects of the physical world (Makransky \& Lilleholt, 2018; J. W. Smith, 2015). VR is one of several innovative technologies receiving attention for its potential use in education and its increasing adoption as a learning tool within classrooms (Meyer, Omdahl, \& Makransky, 2019)(Hu Au \& Lee, 2017); it has been linked to numerous advantages, such as increased motivation, active learning, and reflective thinking. Its educational potential has not been thoroughly investigated; however, given its increasing affordability, this technology is now being used by consumers at home and for training purposes (Meyer et al., 2019; Papanastasiou et al., 2018). The most common mediums to display VR content include desktop, cave automatic virtual environment (CAVE), and headmounted display (HMD). Virtual reality technology is often ranked by how much immersion it can induce; HMD and CAVE systems are typically identified as having higher levels of immersion than desktop systems (Cummings \& Bailenson, 2016).

In general, immersive VR (IVR) technology enables the possibility of representing abstract concepts in a tangible manner while generating students' engagement and motivation in the learning process (Persky \& McBride, 2009). Moreover, VR provides the user with a new context in which to think about their behaviours and responses to the generated environment (S. Smith \& Ericson, 2009).

\subsection{Learning theories and VR}

In the study of VR as a pedagogical tool, different theories provide insights into the advantages or disadvantages of using this technology for learning purposes. Below, we outline these theories.

The theory of embodied cognition suggests that our cognition is influenced, perhaps even determined, by our experiences in the physical world (Review \& Anderson, 2003). Physical interactions and bodily cues can lighten the cognitive load required in the learning 
process, resulting in better task completion and learning outcomes. In other words, this theory implies that there is a connection between our motor and visual senses; therefore, the more explicit the connection, the easier learning becomes (Johnson-Glenberg, 2018; Mayer, 2014). Highly immersive VR systems allow the user to be situated inside the computer-generated environment and to interact with the environment through physical gestures or movements. Thus, IVR would, in theory, provide an advantage for learning.

Additionally, the effect that embodied cognition can have in reducing cognitive load and the possibility of manipulating objects in the 3D environment, achieved via the new generation of IVR hand controllers, gives the learner the unique sensation of agency (i.e., control) over the learning environment (Johnson-Glenberg, 2018). This feeling of agency is also increased by the sense of presence and active participation that IVR allows. Sense of presence is defined as the feeling of being there (Mikropoulos \& Bellou, 2006), which gives the user a first-person experience and nonsymbolic interaction with the learning content, supporting the construction of knowledge under a constructivist point of view (Winn, Windschitl, Fruland, \& Lee, 2002). IVR has the ability to situate the learner inside the learning environment, thereby making them a central, active, and intrinsic participant in the process (Li, Cheng, Wang, He, \& Liang, 2019). Therefore, IVR could generate learning outcomes from the sense of presence, increased agency, and high interactivity that it affords. Furthermore, another learning advantage linked to IVR is in relation to the interest theory, which states that greater engagement, interest, and motivation are often related to positive learning outcomes (Makransky, Borre-Gude, \& Mayer, 2019). Students try harder to learn and solve learning tasks when they are interested in the material presented to them (Harackiewicz, Smith, \& Priniski, 2016; Hidi \& Harackiewicz, 2000; Renninger \& Hidi, 2016), and learning environments can trigger interest and motivation. IVR technology is 
known for its potential to elicit student interest and can create an engaging learning environment (Freina \& Ott, 2015; Makransky, Borre-Gude, et al., 2019).

Additionally, instructional theory states that direct participation helps provide a foundation for novice learners and increases the student's ability to transfer learning to the real world (Dede, Jacobson, \& Richards, 2017). In other words, the possibility for successful learning transfer is increased when students are able to practice what they learned in a similar environment to where the skills are going to be applied (Rupp et al., 2019). Therefore, IVR could be a useful tool to facilitate and leverage the transfer of learning.

Conversely, the cognitive theory of multimedia learning (CTML) and the cognitive load theory (CLT) outline some of the possible disadvantages. CTML is based on three main assumptions: first, the learner's processing capacity is limited; second, learning is an active process of selecting, organising, and integrating information; and third, two different channels (auditory and visual) process information (Makransky, Borre-Gude, et al., 2019). CTML suggests that when cognitive processing goes beyond the learner's capacity, cognition is overloaded and learning is hindered. This idea is consistent with the CLT proposed by Sweller, Ayres, \& Kalyuga (2011), which states that students have limited memory workloads during instruction, and if this capacity is exceeded, the learning process is obstructed. As applied to an IVR environment, the amount of sensory information the user receives while interacting with the virtual world could increase extraneous cognitive load, which could have a negative effect on task completion and learning (Makransky, Terkildsen, \& Mayer, 2019). Indeed, previous research suggests that IVR could impose a greater amount of cognitive load on the user than in less-immersive experiences, and by doing so, it could interfere with the learning process (Richards \& Taylor, 2015).

The contrasting theoretical accounts clearly give reasons to be simultaneously optimistic and cautious about IVR for use in education with children. This contrast hightights 
the importance of experimental research to ascertain under what conditions IVR educational tools may be effective. Indeed this is the underlying current behind the key aim for the paper described below.

\section{Aim}

Various theories, described above, support the premise that an IVR experience could either enhance or hinder children's ability to learn from an immersive 3D environment. This study aimed to investigate whether IVR technologies could be a useful tool to develop and practice problem-solving skills. We compared the rate of success or failure of participants using a problem-solving game (river crossing task) on three different mediums: IVR, a tablet application, and a board game. More specifically, this study sought to answer the following questions: (1) Is IVR a useful tool to learn and practice problem-solving skills? Do children using IVR perform better at solving the game than those using a tablet or a board game? (2) Does IVR provide a more engaging experience for children to practice problem-solving skills than on a tablet or board game? (3) Do problem-solving skills learned with immersive virtual environment technology transfer to real-life (physical game)?

\section{Method and Materials}

\subsection{Participants}

An initial pilot study with 10 participants was conducted to provide a formative evaluation of the procedures and instruments. One hundred and twenty children (61 females, 59 males) aged $7-9.9$ years $(M=8.4$ years, $S D=0.86)$ participated in the formal study. Each participant was randomly assigned to one of the three conditions: board game (BG; $n=40)$, tablet application (tablet; $n=40)$, or IVR $(n=40)$. Families were recruited from the same geographical location of [To be added following double blind review]. The study was approved by the university's Human Research Ethics Committee. All parents provided informed consent for their children's participation; prior to 
beginning each session, the experimenter obtained oral consent from the child and written consent from a parent.

\subsection{Assessment instruments}

Child Simulator Sickness Questionnaire (CSSQ) (Hoeft, Vogel, \& Bowers, 2003): This seven-item instrument was designed to assesses specific symptoms of simulator sickness and is adapted from the original Simulator Sickness Questionnaire for adults (Kennedy, Lane, Berbaum, \& Lilienthal, 1993). The questionnaire poses seven questions relating to potential feelings of sickness (e.g., "Do you have an upset stomach," "Are you dizzy with your eyes closed?," etc.). These questions are divided into three symptom categories (nausea, oculomotor, and disorientation). The questionnaire is scored by allocating each question a value based on the response. Participants can answer, no (score of 0), a little (score of 1), or $a$ lot (score of 2). A score of 3 or more for any of the three symptom categories indicates the presence of simulator sickness symptoms.

Sense of Presence questionnaire for children (SofP) (See Appendix A): To make the SofP suitable for use by children, the research team modified and adapted the adult questionnaire from the ITC-Sense of Presence Inventory (Lessiter, Freeman, Keogh, \& Davidoff, 2001) and the Presence Questionnaire (Witmer \& Singer, 1998). The authors decided not to use the original versions not only because they contained more than 20 items and used sophisticated vocabulary but also many questions did not apply to our IVR experience. Thus, the research team selected the most relevant questions for our project and modified the language used for some of the items to make them easier for the children to understand. The SofP questionnaire for this study contains nine statements about the presence perceived during the VR experience. For example:

- I felt like sounds were coming from different directions, places, all around me.

- I felt I could have touched things in the video. 
Participants could provide three possible answers: yes, a little, or no. Participants could provide three possible answers, recoded as scores from 0 to 2, with higher scores indicating greater sense of presence.

\subsection{Apparatus and software}

The materials for each of the three conditions (BG, tablet, and IVR) were based on a common mathematical game called the River Crossing Game (Bellman, 1962). This game has many variations; however, the simple version used in this research includes a farmer, boat, wolf, goat, and basket of cabbages. The aim of this puzzle game is to carry items from one riverbank to another in as few moves as possible. The conditions imposed on the game include: (a) only one item can be carried at a time, and (b) only some items may be safely left together. For example, if the wolf is left with the goat, the wolf will eat the goat, and if the goat is left with the cabbage, the goat will eat the cabbage. The optimal solution involves seven moves.

Children in the BG condition used a board that had an image of a river and five objects (toy figures of a wolf, goat, cabbage, farmer, and boat) (see Figure 1).

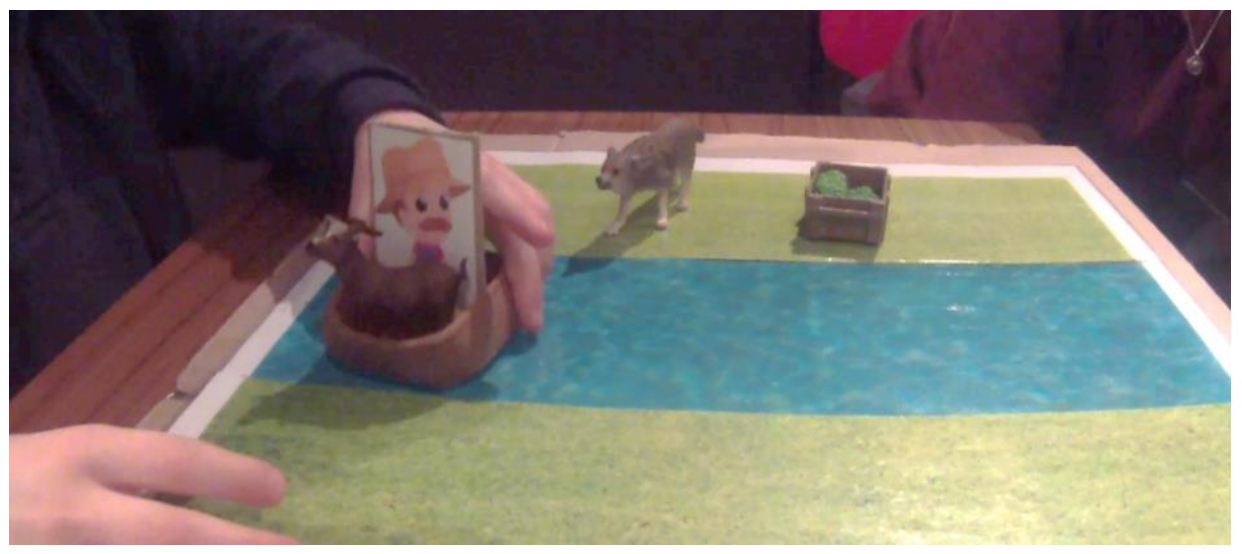

Figure 1. Board game condition. Child playing the River Crossing Game.

Children in the tablet condition used an application called Crossing the River (Song, 2016) on an iPad (see Figure 2). This software is freely available on the Apple Store. This 
application presents the river crossing puzzle with the same characters as the board game.
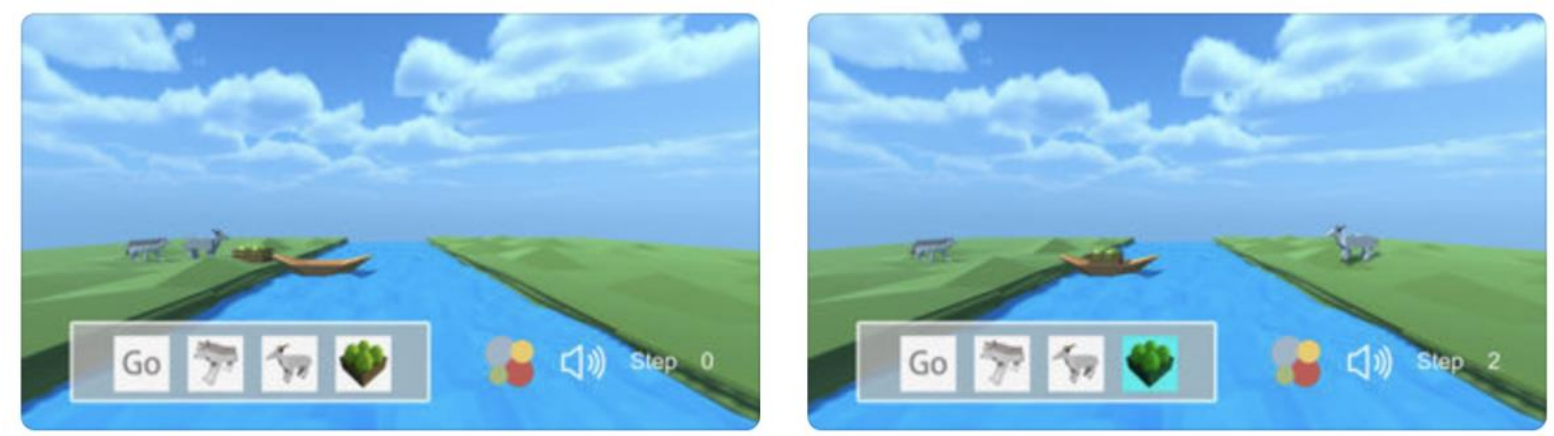

Figure 2. Tablet condition. Screenshots from the river crossing. The left image shows the start of the game, and the right image shows the game in progress.

Children in the IVR condition played the game using an HTC Vive, a VR set with a HMD and handheld controllers (see Figure 3). The headset was used to show the River Crossing Game to the participant, and a separate screen was used to show the view of the participant. This set up allowed the experimenter to follow and manage the IVR environment. Only one control was used to enable the participant to interact with the environment. The IVR version of the River Crossing Game was created by an expert group of $\square$ [To be added following double blind review] university developers specifically for this study The IVR game used the same mathematical principles and the same characters and objects (wolf, sheep, and cabbage) as the other two conditions, except for the farmer. In the case of the IVR condition, the participant becomes the farmer in the game, allowing the participant to control the boat and making him or her part of the game. In contrast, in the other two conditions (BG 
and tablet), the participant directs the game from outside the game, and a farmer is used to control the boat.

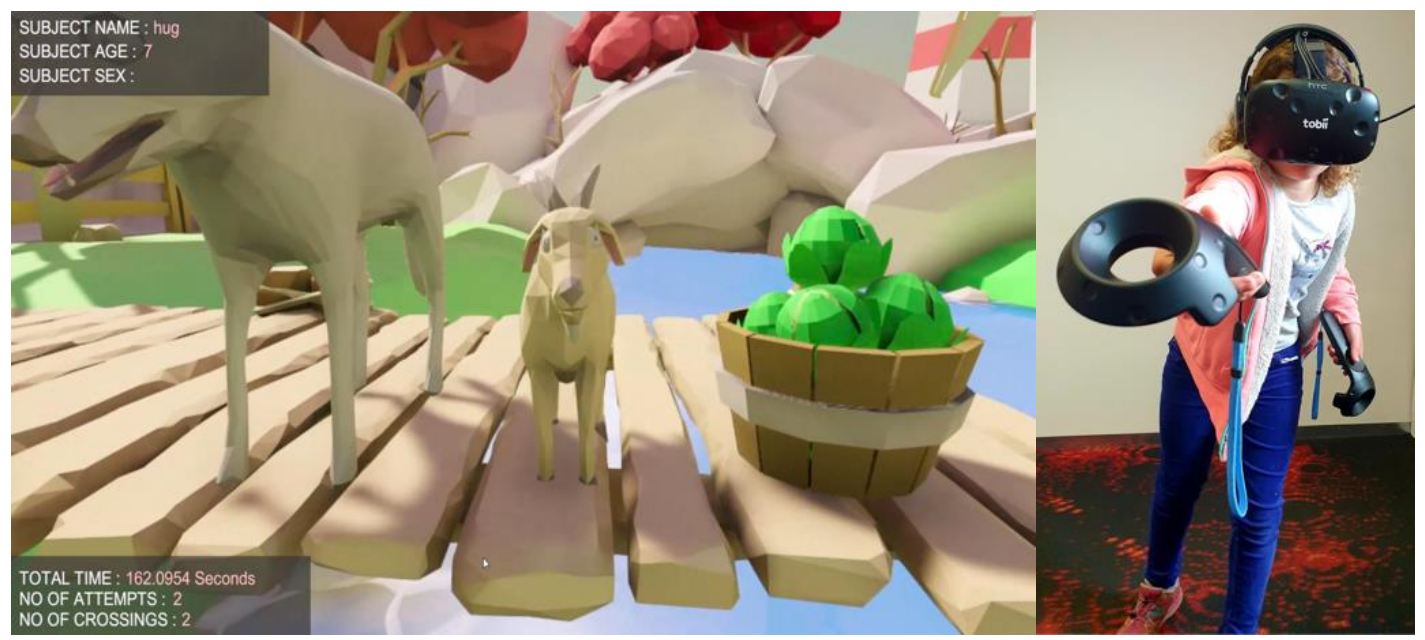

Figure 3. IVR condition. Screenshot of the IVR River Crossing Game on the right, and a participant with the HMD and controllers on the left.

\subsection{Design and procedure}

Parents sat outside the testing room and completed an online demographic form and a media-use questionnaire while their child completed the study in a dedicated room set up for the VR experiment. The demographic survey contained 14 questions related to socioeconomic status, education, ethnicity, and language spoken at home, while the mediause questionnaire comprised questions about the child's previous use of IVR technology.

The room with the VR equipment had a free space of $4 \mathrm{~m} \times 4 \mathrm{~m}$ where the participants could use the HMD and safely move around without obstruction. The HMD cable was hooked to the ceiling to prevent tripping or entangling.

The experiment included four phases conducted in the following order: (1) warm-up phase, (2) stimuli phase (problem-solving game), (3) distraction phase, and (4) transfer-oflearning phase (see Figure 4). 


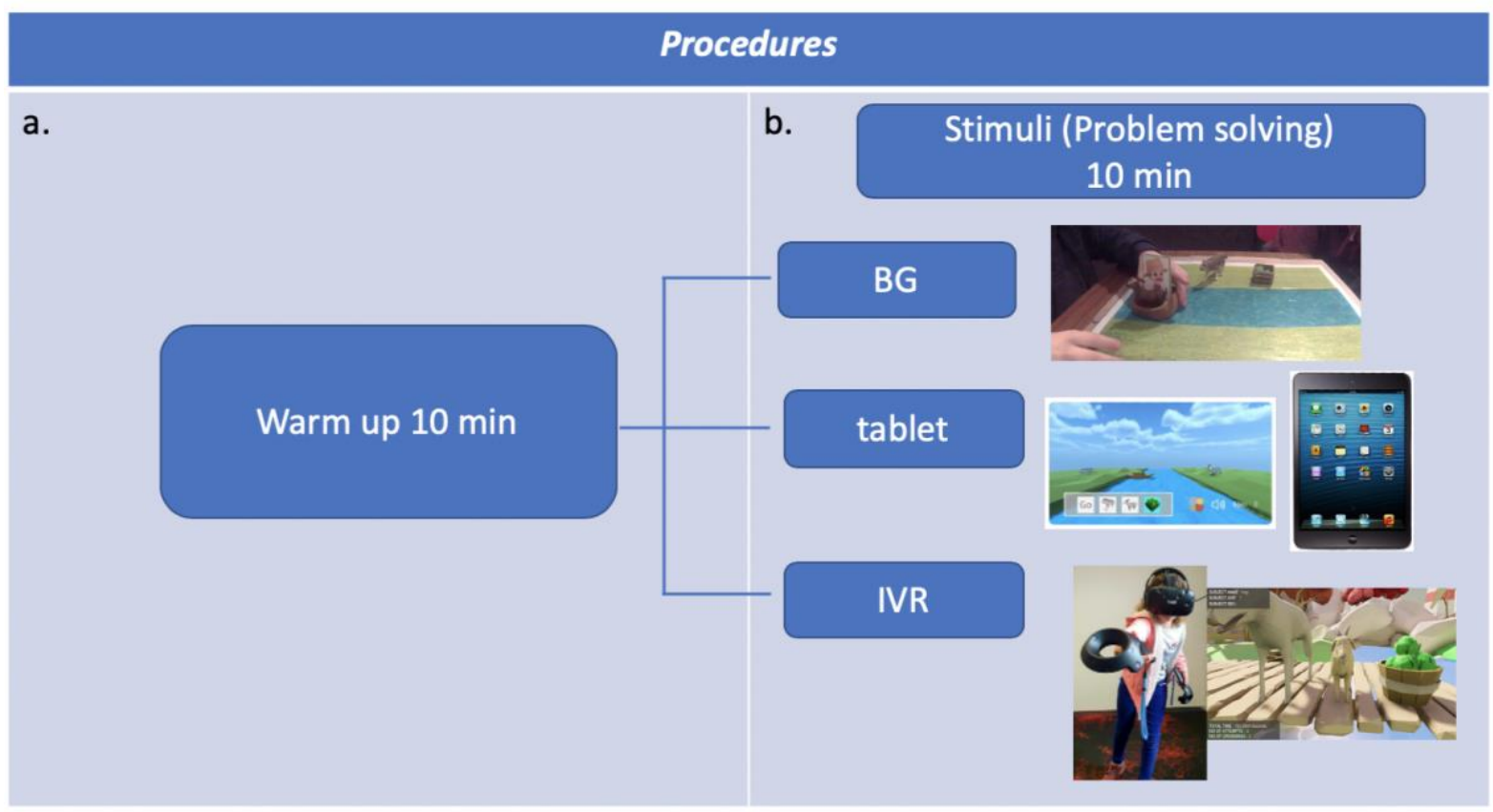

c.
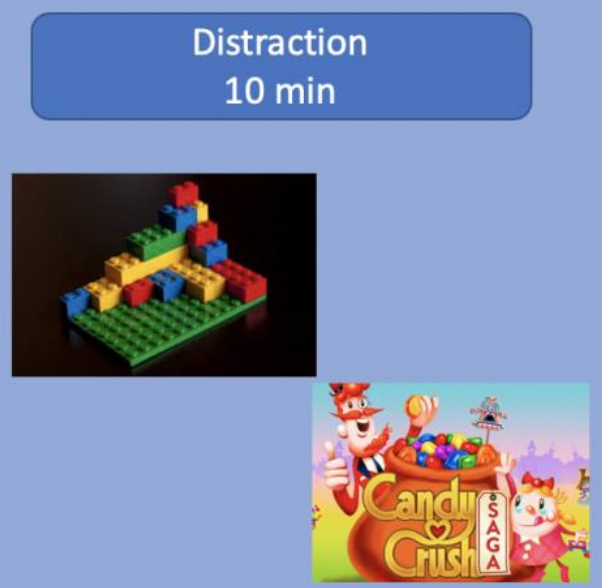

d.

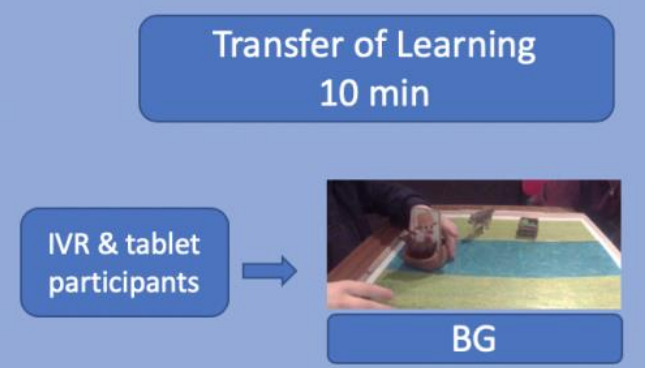

BG participants

Figure 4. Description of the study procedures. $\mathrm{BG}=$ board game, IVR = immersive VR.

Phases of the study:

a. Warm-up phase $(10 \mathrm{~min})$ : A female researcher introduced herself to and played games with the child for approximately 5 min (Tic-tac-toe/noughts and crosses). While playing, the researcher asked the child some questions to establish rapport (e.g., How old are you? Which sports do you like? Do you have siblings?). Then, the researcher carried out the CSSQ (see Method and Materials) with the child. All 
participants scored less than 3 on the CSSQ, so all moved on to the problem-solving phase of the experiment.

b. Stimuli phase (problem-solving) (10 $\mathrm{min})$ : Children were randomly assigned to one of the three conditions: BG, tablet, or IVR, as described in the Method and Materials section.

In the BG condition, the researcher explained to the participant that they would be playing a problem-solving game called the River Crossing Game, and presented the board and the toy figures. Then, the participant was given the instructions for the game, and a timer was started to record the time that the participant took to solve the problem. If 5 min passed without the participant solving the game, the researcher provided a hint and said, "I am going to give you a clue: you can bring things back in the boat." The experimenter then waited another 5 min for the participant to solve the problem. If the participant did not solve the problem by the 10-min mark or gave up before the time finished, the researcher showed the solution to the game. The tablet condition was conducted in the same manner, using an iPad.

In the IVR condition, the researcher explained to the participant that they would be playing a problem-solving game called the River Crossing Game using VR goggles and controls. Then, the researcher demonstrated to the participant how to use the controls and how to identify the boundaries of the room while using the HMD to avoid any contact with the walls. The HMD display was fitted on the participant's head, and the controls were handed to the participant. The participant was given 5 min in a VR sandbox to acclimatise to the VR environment and practice using the controls. The researcher commenced the IVR game and started the timer to record the time the participant took to solve the problem; hints and offered solutions aligned with the times shown in the BG and tablet conditions. 
a. Distraction phase: The subsequent distraction phase was $10 \mathrm{~min}$ of free play. During free play, children could choose to independently play with LEGOC pieces or Candy Crush (on the iPad). After 5 min of free play, the researcher asked them questions relating to their enjoyment during the previous activity using an enjoyment and engagement questionnaire. This questionnaire contained four questions aimed to determine how much the child enjoyed the activity and whether they would have preferred to play it in a different modality (e.g., VR instead of on the tablet) (see Appendix B). The purpose of this phase was to record their level of enjoyment and engagement with the task while creating an interval between the stimulus (problemsolving game) and the transfer-of-learning phases. For the participants in the IVR condition, the researcher also completed the SofP questionnaire with the child (see Appendix A).

c. Transfer-of-learning phase: During this phase, the researcher asked the child to solve the River Crossing Game again but in a different modality from the stimuli phase. Hence, participants in the IVR and tablet conditions during the stimuli phase were asked to solve the problem using the board game, and the participants in the BG condition were asked to solve the game using the IVR headset (see Figure 4). The authors decided to not use the tablet during this phase because there is already ample research on transfer of learning to tablet apps (e.g., Huber et al. (2016);

added following double blind review]; therefore, we focused on examining the transfer to IVR.

\subsection{Coding}

From the video and screen recordings of testing sessions, all the boat movements that the participant used to solve the problem were coded, documenting whether the participant solved the problem, gave up before the time finished, or did not solve it by the 10-min mark. 
Participants who solved the problem after the first 5 min with the help of the hint were mark as solved with the hint; participants who solved before the 5-min mark were coded as solved without the hint; participants who did not solve the problem were marked as not solved; and those who gave up were marked as gave up. This coding was done in the same way for all the participants in the stimuli and transfer-of-learning phases. For both the tablet and IVR conditions, coding the number of moves was automatically done by the technology; for the BG condition, the majority of participants were coded by a single coder (first author), and an additional coder independently coded $40 \%$ of the BG trials for rater reliability, revealing $100 \%$ agreement with the first coder on all coder measures.

\section{Results}

One hundred and thirty-six children participated in the study. Sixteen children were excluded from the analyses because of the following reasons: the child knew the answer to the game $(n=9)$, the child did not want to use the IVR equipment because he/she was scared of the wolf in the game (i.e., the wolf looks scary, too real, he would get me; $n=4$ ), and procedural error $(n=3)$. The final data set of the study included 120 participants: 61 girls and 59 boys aged $7-9.9$ years $(M=8.4$ years, $S D=0.86$ years $)$. Each participant was randomly assigned to one of the three conditions, $\mathrm{BG}(n=40, M=8.43$ years, $S D=0.89$ years $)$, tablet ( $n=40, M=8.46$ years, $S D=0.88$ years), or IVR ( $n=40, M=8.3$ years, $S D=0.84$ years).

The demographic and media-use survey completed by the parents indicated that $59.5 \%$ of children in this study had previously used an IVR headset; among these participants, $41 \%$ had used it on only a single occasion, $42 \%$ had used it between two and four times, and $16 \%$ had done so more than five times. Most parents $(70 \%)$ reported having completed a tertiary degree.

Preliminary analyses revealed neither significant main effects of the child's sex or age nor interactions with sex or age on the key dependent measures (performance, interest and 
enjoyment, and transfer of learning); therefore, sex and age were not included as covariates in subsequent analyses.

\subsection{Performance outcomes}

To determine whether more children using IVR solved the game than those in either the tablet or BG conditions, a chi-square test of independence was conducted using the binary variable solved-not solved as the outcome variable. A statistically significant difference was found in the proportion of children who solved the river crossing task across conditions $\left(\chi^{2}(2)=22.97, p<.001\right)$. Figure 5 shows that the majority of the participants in the IVR condition $(77.5 \%)$ solved the problem successfully, compared with those in the tablet $(32.5 \%)$ and $\mathrm{BG}(30 \%)$ conditions.

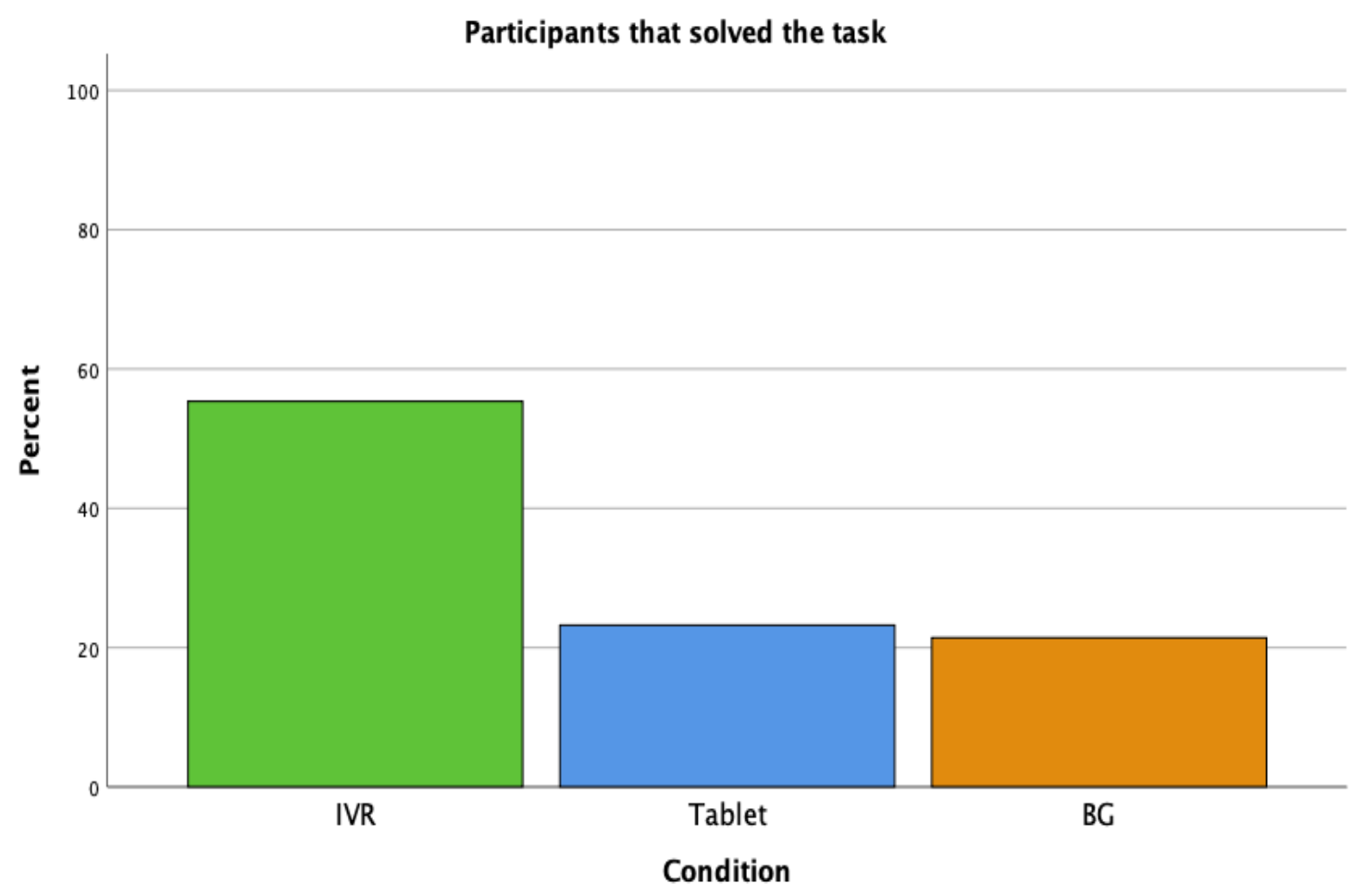

Figure 5. Bar graph showing the results of the percentage of participants who solved the problem-solving game per conditions. $\mathrm{BG}=$ board game, $\mathrm{IVR}=$ immersive VR. 
In relation to the number of moves taken to solve the task, a Kruskal-Wallis test indicated a statistically significant difference in the distribution of number of moves (among those who solved the problem successfully) across conditions $(H(2)=10.33, p=.006)$. A Mann-Whitney test subsequently revealed a significant difference in the distribution of the number of moves between IVR and tablet conditions $(U=76.50, p=.001)$. Children in the IVR condition used fewer moves to solve the game than the children using the tablet. No statistically significant difference was found in the number of moves between the BG and the other two conditions (see Figure 6). Two outliers were found in the BG condition; the researchers decided to include them in the analysis, as further analysis of the data without the outliers did not reveal any differences.

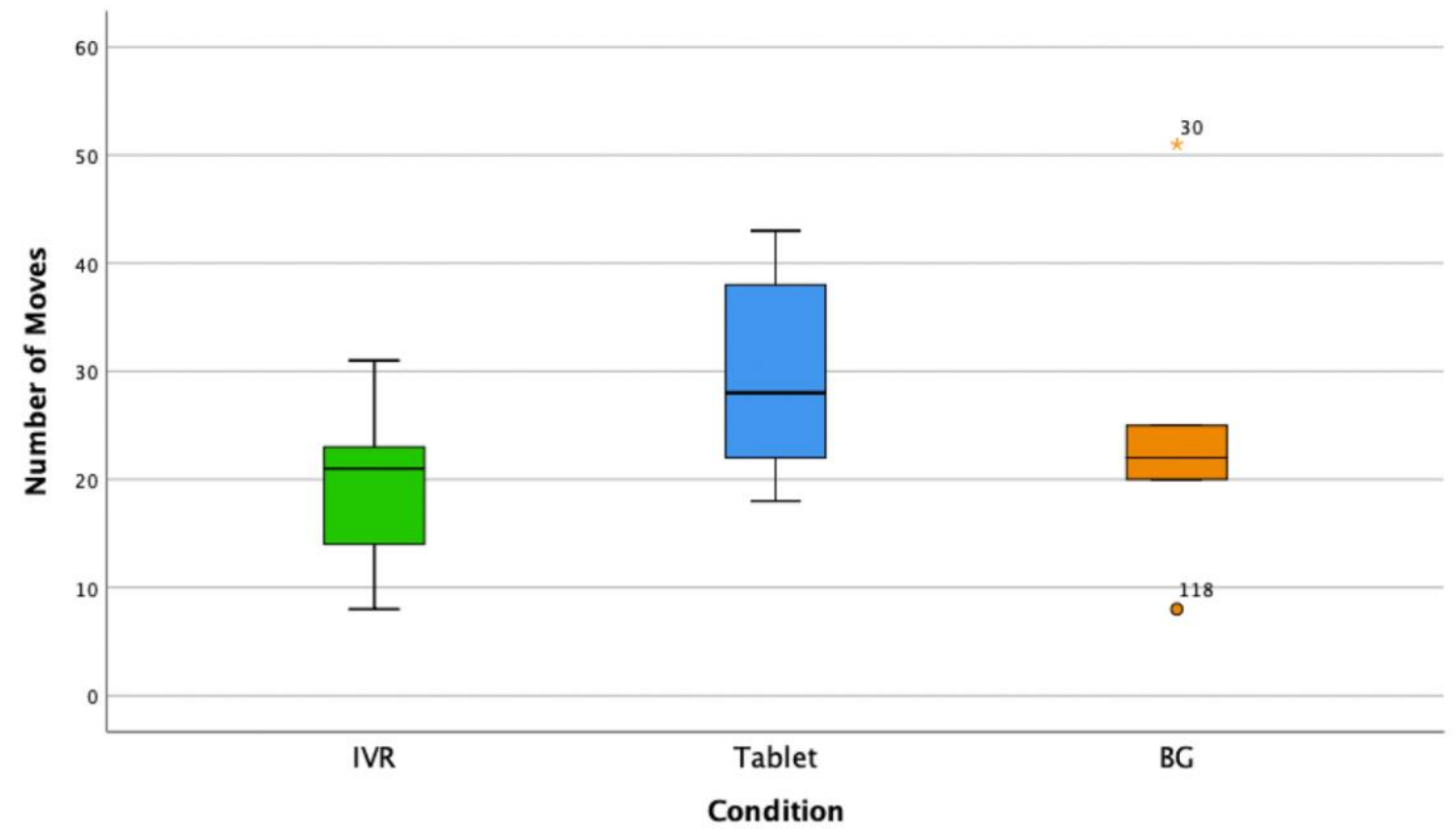

Figure 6 . Box plot of the number of moves per condition. $\mathrm{BG}=$ board game, $\mathrm{IVR}=$ immersive VR.

A Chi-square test of independence was performed to examine the relationship between condition and performance. The relationship between these variables was significant, $X^{2}(6)=24.44, p<.001$. The performance of children in the IVR condition was 
found to be significantly different than children in the other two conditions $X^{2}(3)=23.50, p$ $<.001$. Children in the IVR condition (7.5\%) gave up the least often in solving the River Crossing Game when compared with children in the other two conditions: tablet (30\%) and BG (30\%) (see Figure 7).

\section{PERFORMANCE ACROSS CONDITIONS}

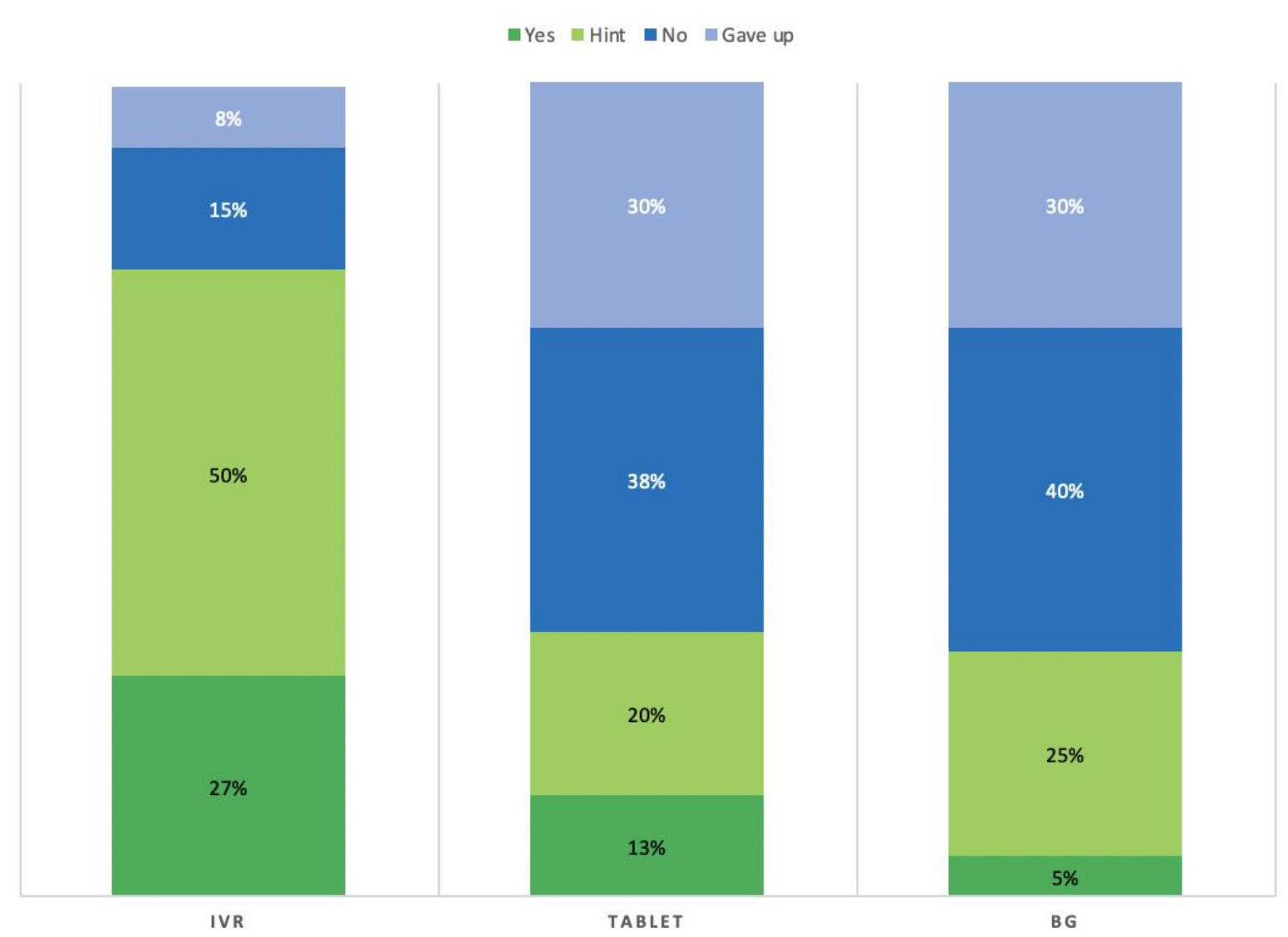

Figure 7. Stacked bar chart of the percentage of participants who solved the game with or without the hint and the ones who did not solve it or gave up. BG = board game, IVR = immersive VR.

\subsection{Interest and enjoyment}

A Kruskal-Wallis test indicated that there was a statistically significant difference in the distribution of interest and enjoyment scores across the conditions $(H(2)=12.01, p$ $=.002$ ). Follow-up Mann-Whitney tests revealed that children in the IVR condition expressed 
greater interest and enjoyment than children in both the tablet condition $(\mathrm{U}=457.00, \mathrm{p}$ $=.001)$ and the $B G$ condition $(\mathrm{U}=601.00, \mathrm{p}=.041)$ (see Figure 8).

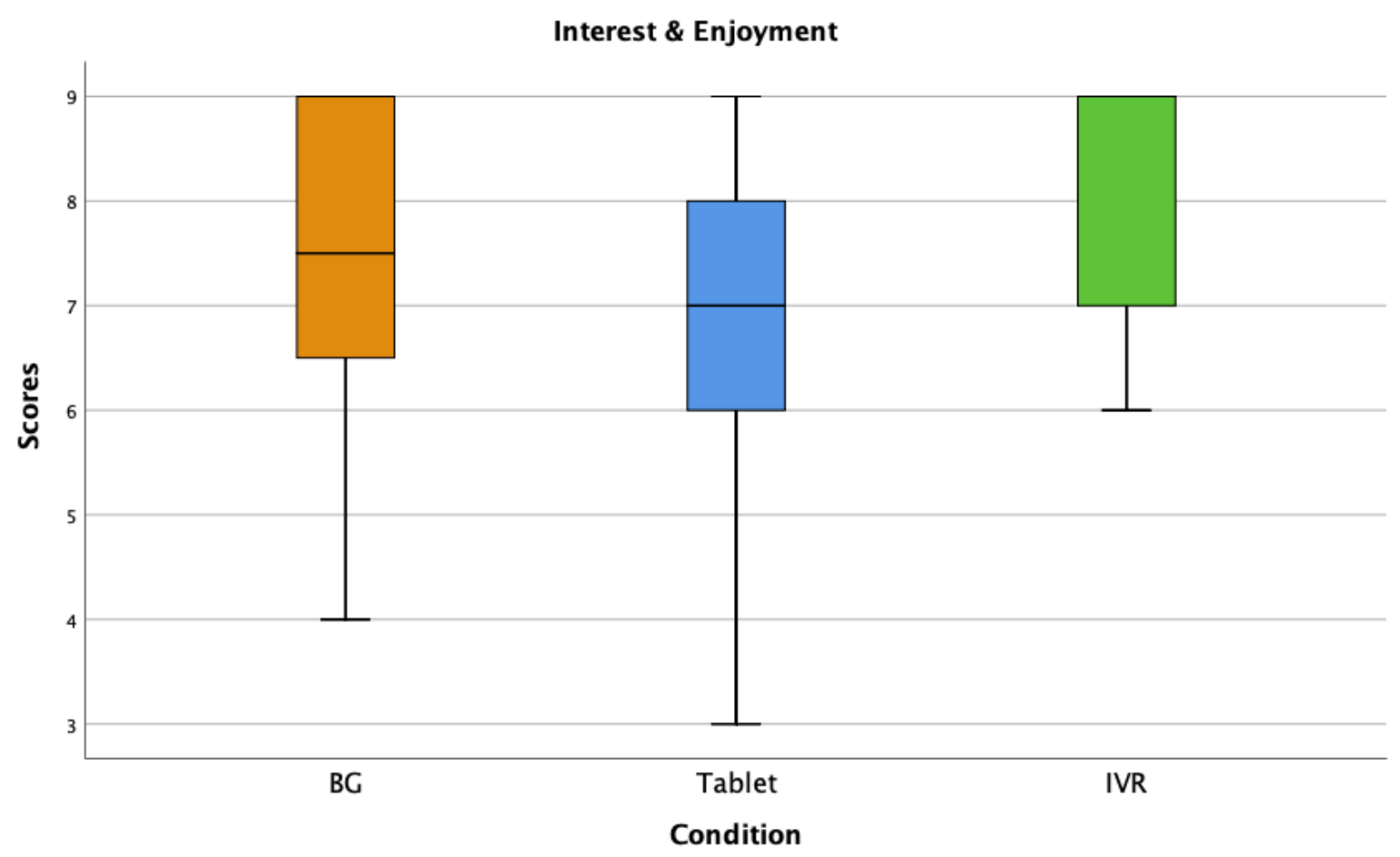

Figure 8. Box plot of the scores of interest and enjoyment per condition. BG = board game, IVR = immersive VR.

\subsection{Transfer of learning}

A Kruskal-Wallis test was conducted to determine if children were able to transfer learning from the two media conditions (IVR and tablet) to the physical game (BG), measured by their performance in solving the problem. More specifically, the number of moves the participants from the two media conditions (training conditions) used to solve the problem were compared with the number of movements the participants took in the BG condition (no training). The test indicated that there was a statistically significant difference in the distribution of the total number of moves across conditions $(H(2)=37.64, p<.001)$. Using the Mann-Whitney test, we found strong evidence for a difference in the distribution of moves between the IVR and the BG conditions; participants in the IVR condition used fewer 
moves than those using the board game $(U=27.00, p<.01)$. Additionally, we found a difference in the distribution of moves between the tablet and the board game; children using the tablet used fewer moves than those using the board game $(U=15.50, p<.001)$. No statistically significant difference was detected between the tablet and IVR groups in transfer performance $(U=693.00, p=.350)$ (see Figure 9).

\section{Mean of moves in board game per training condition}

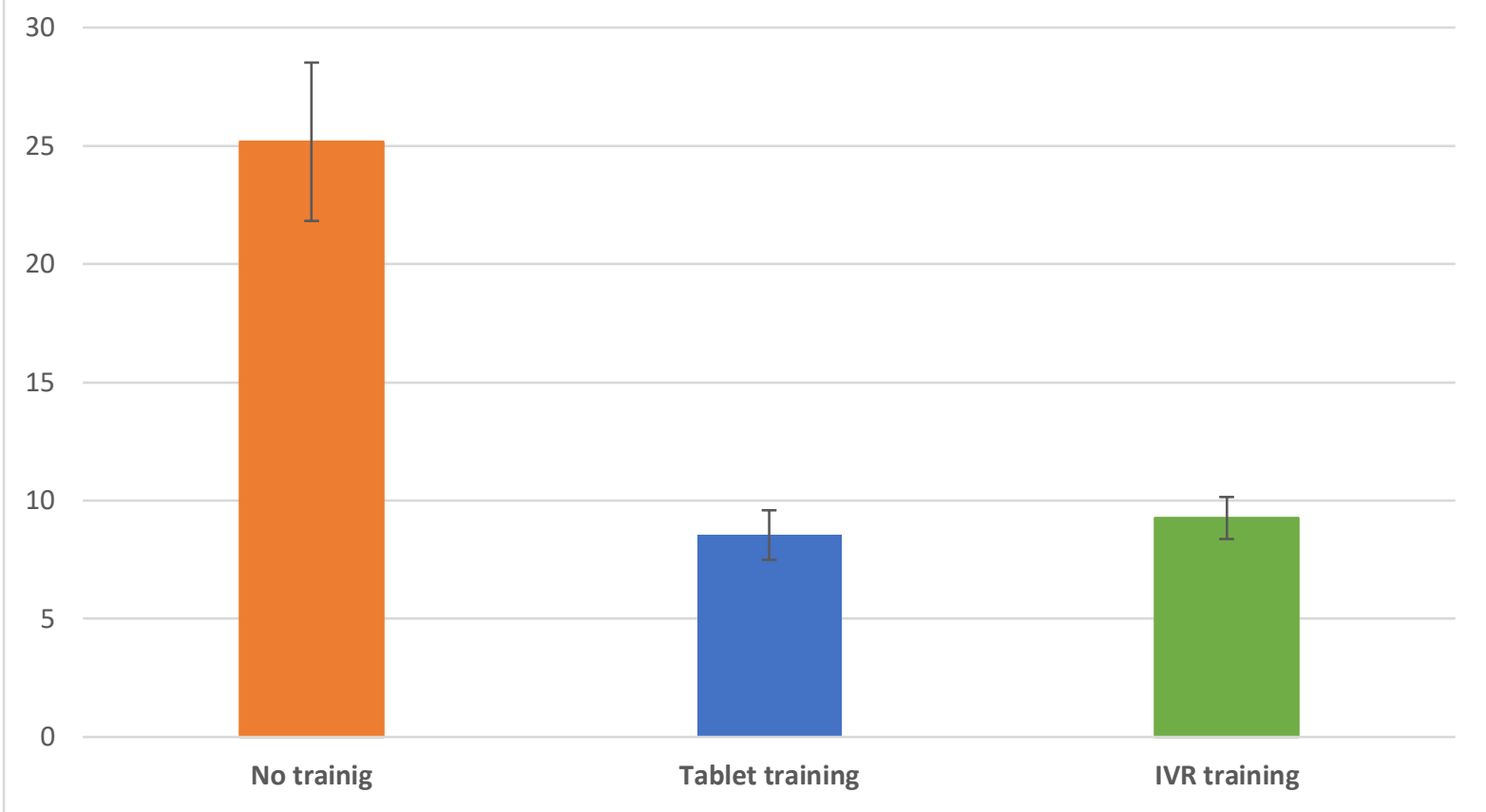

Figure 9. Bar chart of the mean of movements on the board game after training in each of the conditions, and the standard error. $\mathrm{BG}=$ board game, IVR = immersive VR.

\subsection{Sense of presence}

Results of the SofP questionnaire revealed that the majority of the participants felt moderate to high levels of sense of presence $(M=13.20, S D=2.98)$, with $65 \%$ of the participants scoring at least 13 of 18 points.

\section{Discussion}


The purpose of this study was to determine whether IVR could be a useful tool to teach and practice problem-solving skills. The results are discussed as they pertain to each of the study aims and research questions identified in the Aims section.

The performance outcomes indicated that children in the IVR condition performed better at solving the task than the children in the tablet or BG conditions. Also, a smaller number of IVR participants gave up solving the problem.

One possible explanation for a performance difference could be linked to the theory of embodied cognition. IVR technology has the capacity to situate the user inside the computer-generated environment and allow interaction with the environment through physical gestures or movements that resemble natural human movements. Physical interaction and bodily cues can assist cognitive processing. The natural feeling that IVR technology can provide to the user could reduce the cognitive load because the user is directly immersed in the VR environment and requires less active imagination and effort to understand the VR world and the objects in it (Shibli \& West, 2018). This characteristic could free cognitive resources that can instead be used to solve the task.

Results related to the interest and enjoyment perceived by the participants can also help us understand why children using IVR performed better in the problem-solving task. IVR has the ability to stimulate the senses of the participants and present the information in a more realistic and authentic manner, resulting in increased interest and willingness to interact with the VR content or environment (Allcoat \& Adrian, 2018; Mantovani \& Castelnuovo, 2003). Moreover, when children are interested in the material that is presented to them, they try harder to learn and solve learning tasks (Harackiewicz et al., 2016; Hidi \& Harackiewicz, 2000; Renninger \& Hidi, 2016). Interest and motivation can be triggered by the environment of the medium used, and IVR technology is known for its potential to elicit the interest of students when used as a tool for active engagement (Freina \& Ott, 2015; Makransky, Borre- 
Gude, et al., 2019). In our study, the children in the IVR condition persevered longer to solve the task than in the other two conditions, where more children gave up within the 10 minutes.

Moreover, our results suggest that learning how to solve a problem-solving task and transferring the learning to the physical world is possible using IVR. Children in the IVR condition (as well as those in the tablet condition) were able to transfer the problem-solving knowledge learned during training to the physical board game. While transfer of problemsolving knowledge from tablets has previously been established (cite Huber, cite Tarasuik, cite Wang), the finding that children transfer from a VR simulation is an important new and relatively new finding. Our results align with Dede et al., (2017), who found that IVR technology allows direct interactive experiences that provide a foundation for novice learners to be able to remember and transfer the learning to a real situation.

\section{Limitations and future directions}

Our study presents two main limitations for testing learning transfer. The first limitation is related to the short time frame $(10 \mathrm{~min})$ between the stimuli phase and the transfer-of-learning phase. We made this logistical decision so that participants only had to visit the lab once, since the loss of participants for follow-up visits is a common problem in research (Becker, Guitton, \& Ring, 2014; Norvell, Dettori, \& Chapman, 2016). When testing children, parents typically need to make different arrangements (at school and work) to bring their children to the lab, and research involving more than one visit is much harder to recruit and retain participants for (Roy et al., 2013). Therefore, the research team decided to design the study without a follow-up visit, so testing the transfer of learning after a longer period of time was impossible. Since the degree of learning is correlated with the retention time (Kamuche \& Ledman, 2005), a future study could look at increasing the time between the 
learning experience and transfer of learning to determine if, by using IVR, children can retain learning for longer periods than when using other mediums.

A second limitation in this study was the type of problem-solving game used and the type of learning measured in the transfer-of-learning task. We used a basic level with a minimal number of characters for this study; therefore, when the children understood and learned that they could bring items back in the boat, it became relatively easy for them to apply the learning to the physical game. The complexity of the River Crossing Game can be increased by adding a new character, so using a more advanced level on the transfer task could leverage the complexity of the game and allow testing of adaptability or flexible thinking skills. Thus, a future study could use either a higher level of difficulty of the River Crossing Game as a transfer-of-learning measure or a different game that involves the same type of solving paradigm. In doing so, adaptation, understanding, and transfer of knowledge could be more efficiently tested because the children must not only remember the solution of the game but also apply the learning to a new situation or an unfamiliar problem.

Another possibility for future research is related to one issue raised by a reviewer. In the distraction phase, children used a tablet device, and this technology was also used in the experimental procedure. Therefore, the authors cannot rule out whether using the device in the distraction phase affected the experimental results; future research could avoid using experimental equipment in the experimental phase, and by doing so, remove any possible confounding factors.

\section{Conclusion}

Overall, IVR is a useful medium as a tool to learn and practice problem-solving skills, which may be due to its ability to stimulate the senses of the user and present the information in a more realistic manner. An IVR learning environment provides a global frame of reference and places less of a cognitive load on children's minds, thereby giving children a 
better opportunity to understand and remember information presented through IVR than through other modalities. In other words, IVR technology is capable of engaging and motivating the user while also supporting cognitive processing and the transfer of knowledge.

\section{Acknowledgements}

To be added following double blind review.

\section{Statements on open data, ethics, and conflict of interest}

Anonymised data from this study is available upon request from the lead author. The study carried out in line with research ethics procedures at To be added following double blind review] and was approved by Human Research Ethics Committee (SHR Project 2018/194). The authors report no conflict of interest. 


\section{References}

Allcoat, D., \& Adrian, von M. (2018). Learning in virtual reality: Effects on performance, emotion and engagement. Research in Learning Technology, 26(1063519), 1-13. https://doi.org/https://doi.org/10.25304/rlt.v26.2140

Becker, S. J. E., Guitton, T. G., \& Ring, D. (2014). Predictors of missed research appointments in a randomized placebo-controlled trial. The Archives of Bone and Joint Surgery, 2(3), 192-198. Retrieved from http://www.ncbi.nlm.nih.gov/pubmed/25386581

Bellman, R. (1962). Dynamic Programming and "Difficult Crossing” Puzzles. Mathematics Magazine, 35(1), 27. https://doi.org/10.2307/2689096

Brocki, K. C., \& Bohlin, G. (2004). Executive functions in children aged 6 to 13: A dimensional and developmental study. Developmental Neuropsychology, 26(2), 571593. https://doi.org/10.1207/s15326942dn2602_3

Crockett, L., Jukes, I., \& Churches, A. (2011). Literacy Is NOT Enough: 21 st Century Fluencies for the Digital Age. Retrieved from http://books.google.com/books?id=JIigZwEACAAJ\&pgis=1

Cummings, J. J., \& Bailenson, J. N. (2016). How Immersive Is Enough? A Meta-Analysis of the Effect of Immersive Technology on User Presence. Media Psychology, 19(2), 272309. https://doi.org/10.1080/15213269.2015.1015740

Dede, C. J., Jacobson, J., \& Richards, J. (2017). Introduction: Virtual, Augmented, and Mixed Realities in Education. https://doi.org/10.1007/978-981-10-5490-7_1

Freina, L., \& Ott, M. (2015). A Literature Review on Immersive Virtual Reality in Education: State Of The Art and Perspectives. Retrieved from http://www.google.com/patents/US3050870

Gretter, S., \& Yadav, A. (2016). Computational Thinking and Media \& Information Literacy: An Integrated Approach to Teaching Twenty-First Century Skills. TechTrends, 60(5), 
510-516. https://doi.org/10.1007/s11528-016-0098-4

Harackiewicz, J. M., Smith, J. L., \& Priniski, S. J. (2016). Interest Matters: The Importance of Promoting Interest in Education. Policy Insights from the Behavioral and Brain Sciences, 3(2), 220-227. https://doi.org/10.1177/2372732216655542

Hidi, S., \& Harackiewicz, J. M. (2000). Motivating the Academically Unmotivated: A Critical Issue for the 21st Century. Review of Educational Research, 70(2), 151-179. https://doi.org/10.3102/00346543070002151

Hoeft, R. M., Vogel, J., \& Bowers, C. a. (2003). Kids Get Sick Too: A Proposed Child Simulator Sickness Questionnaire. Proceedings of the Human Factors and Ergonomics Society Annual Meeting, 47(20), 2137-2141. https://doi.org/10.1177/154193120304702013

Hu Au, E., \& Lee, J. J. (2017). Virtual reality in education: a tool for learning in the experience age. International Journal of Innovation in Education, 4(4), 215. https://doi.org/10.1504/ijiie.2017.10012691

Johnson-Glenberg, M. (2018). Immersive VR and education: Embodied design principles that include gesture and hand controls. Frontiers Robotics AI, 5(JUN), 81. https://doi.org/10.3389/frobt.2018.00081

Kalyuga, S., Renkl, A., \& Paas, F. (2010, April 30). Facilitating flexible problem solving: A cognitive load perspective. Educational Psychology Review, Vol. 22, pp. 175-186. https://doi.org/10.1007/s10648-010-9132-9

Kamuche, F. U., \& Ledman, R. E. (2005). Relationship of Time and Learning Retention. Journal of College Teaching \& Learning (TLC), 2(8). 
Kennedy, R. S., Lane, N. E., Berbaum, K. S., \& Lilienthal, M. G. (1993). Simulator Sickness Questionnaire: An Enhanced Method for Quantifying Simulator Sickness. The International Journal of Aviation Psychology, 3(3), 203-220.

https://doi.org/10.1207/s15327108ijap0303_3

Lessiter, J., Freeman, J., Keogh, E., \& Davidoff, J. (2001). A Cross-Media Presence Questionnaire: The ITC-Sense of Presence Inventory. Presence: Teleoperators and Virtual Environments, 10(3), 282-297. https://doi.org/10.1162/105474601300343612

Li, Z., Cheng, X., Wang, L., He, H., \& Liang, B. (2019). The Application of Student Participation in the Design of Virtual Reality Educational Products. Lecture Notes in Computer Science (Including Subseries Lecture Notes in Artificial Intelligence and Lecture Notes in Bioinformatics), 11585 LNCS, 444-456. https://doi.org/10.1007/978-3030-23538-3_34

Luria, A. (1966). Higher Cortical Functions in Man. New York, NY: Oxford University Press.

Makransky, G., Borre-Gude, S., \& Mayer, R. E. (2019). Motivational and cognitive benefits of training in immersive virtual reality based on multiple assessments. Journal of Computer Assisted Learning, (December 2018), 1-17. https://doi.org/10.1111/jcal.12375

Makransky, G., \& Lilleholt, L. (2018). A structural equation modeling investigation of the emotional value of immersive virtual reality in education. Educational Technology Research and Development, 66(5), 1141-1164. https://doi.org/10.1007/s11423-018- 
$9581-2$

Makransky, G., Terkildsen, T. S., \& Mayer, R. E. (2019). Adding immersive virtual reality to a science lab simulation causes more presence but less learning. Learning and Instruction, 60, 225-236. https://doi.org/10.1016/j.learninstruc.2017.12.007

Mantovani, F., \& Castelnuovo, G. (2003). Sense of Presence in Virtual Training: Enhancing Skills Acquisition and Transfer of Knowledge through Learning Experience in Virtual Environments. Being There: Concepts, Effects and Measurement of User Presence in Synthetic Environments, (January), 168-181.

Mayer, R. E. (2014). Principles based on social cues in multimedia learning: Personalization, voice, image, and embodiment principles. In The Cambridge Handbook of Multimedia Learning, Second Edition (pp. 345-368). https://doi.org/10.1017/CBO9781139547369.017

Meyer, O. A., Omdahl, M. K., \& Makransky, G. (2019). Investigating the effect of pretraining when learning through immersive virtual reality and video: A media and methods experiment. Computers and Education, 140(June), 103603. https://doi.org/10.1016/j.compedu.2019.103603

Mikropoulos, T. A., \& Bellou, J. (2006). The unique features of educational virtual environments. Teaching and Learning with Technology: Beyond Constructivism, 249258. https://doi.org/10.4324/9780203852057

Norvell, D. C., Dettori, J. R., \& Chapman, J. R. (2016). Enhancing Clinical Study Retention Rates to Avoid Follow-up Bias: How Do We Keep Our Study Participants from the Land of the Lost? Global Spine Journal, 6(5), 519-521. https://doi.org/10.1055/s-00361584928

Papanastasiou, G., Drigas, A., Skianis, C., Lytras, M., \& Papanastasiou, E. (2018). Virtual and augmented reality effects on K-12, higher and tertiary education students' twenty- 
first century skills. Virtual Reality, 23(4), 425-436. https://doi.org/10.1007/s10055-0180363-2

Pellegrino, J. W., \& Hilton, M. L. (2012). Education for Life and Work: Developing Transferable Knowledge and Skills in the 21st Century. Retrieved from http://www.nap.edu/catalog.php?record_id=13398

Persky, S., \& McBride, C. M. (2009). Immersive virtual environment technology: a promising tool for future social and behavioral genomics research and practice. Health Communication, 24(February 2015), 677-682. https://doi.org/10.1080/10410230903263982

Renninger, A. K., \& Hidi, S. (2016). The power of interest for motivation and engagement. In The Power of Interest for Motivation and Engagement. https://doi.org/10.4324/9781315771045

Review, F., \& Anderson, M. L. (2003). Embodied Cognition: A field guide. Artificial Intelligence, 149,125 . https://doi.org/10.1016/S0004-3702(03)00054-7

Richards, D., \& Taylor, M. (2015). A Comparison of learning gains when using a 2D simulation tool versus a 3D virtual world: An experiment to find the right representation involving the Marginal Value Theorem. Computers and Education, 86, 157-171. https://doi.org/10.1016/j.compedu.2015.03.009

Roy, A., Lieb, W., Garrett, B., Hodik, M., Klipsch, A., Young, M., ... Schwarz, K. B. (2013). Recruitment and retention strategies in a clinical trial for children with chronic hepatitis c infection. Journal of Pediatric Nursing, 28(3), 243-248. https://doi.org/10.1016/j.pedn.2012.08.006

Rupp, M. A., Odette, K. L., Kozachuk, J., Michaelis, J. R., Smither, J. A., \& McConnell, D. S. (2019). Investigating learning outcomes and subjective experiences in 360-degree videos. Computers and Education, 128(February 2018), 256-268. 
https://doi.org/10.1016/j.compedu.2018.09.015

Sanabria, J. C., \& Arámburo-Lizárraga, J. (2017). Enhancing 21st century skills with AR:

Using the gradual immersion method to develop collaborative creativity. Eurasia Journal of Mathematics, Science and Technology Education, 13(2), 487-501. https://doi.org/10.12973/eurasia.2017.00627a

Serino, A., Ciaramelli, E., Di Santantonio, A., Malagù, S., Servadei, F., \& Làdavas, E. (2006). Central executive system impairment in traumatic brain injury. Brain Injury, 20(1), 23-32. https://doi.org/10.1080/02699050500309627

Shibli, D., \& West, R. (2018). Cognitive Load Theory and its Application in the Classroom. Journal of the Chartered College of Teaching, 2(Science of Learning). Retrieved from https://impact.chartered.college/article/shibli-cognitive-load-theory-classroom/

Smith, J. W. (2015). Immersive virtual environment technology to supplement environmental perception, preference and behavior research: A review with applications. International Journal of Environmental Research and Public Health, 12(9), 11486-11505. https://doi.org/10.3390/ijerph120911486

Smith, S., \& Ericson, E. (2009). Using immersive game-based virtual reality to teach firesafety skills to children. Virtual Reality, 13(2), 87-99. https://doi.org/10.1007/s10055009-0113-6

Song, W. (2016). Crossing the river -A casual strategy game on the App Store. Retrieved from https://apps.apple.com/au/app/crossing-the-river-a-casual-strategygame/id1152901805

Sweller, J., Ayres, P., \& Kalyuga, S. (2011). Categories of Knowledge: An Evolutionary Approach. In Cognitive Load Theory (pp. 3-14). https://doi.org/10.1007/978-1-44198126-4_1 
Winn, W., Windschitl, M., Fruland, R., \& Lee, Y. (2002). When Does Immersion ina a virtual Environmment Helps Students construct Understanding? ICLS 2002, 497-503. Retrieved from https://www.isls.org/icls/2002/

Witmer, B. G., \& Singer, M. J. (1998). Measuring Presence in Virtual Environments: A Presence Questionnaire. In Presence (Vol. 7). Retrieved from https://nil.cs.uno.edu/publications/papers/witmer1998measuring.pdf

Yu, K. C., Fan, S. C., \& Lin, K. Y. (2015). Enhancing students' problem-solving skills through context-based learning. International Journal of Science and Mathematics Education, 13(6), 1377-1401. https://doi.org/10.1007/s10763-014-9567-4 


\section{Appendices}

\section{Appendix A}

Sense of Presence Questionnaire

Read the following to the child and circle one of the answers base on their response.

After your experience with the goggles:

\begin{tabular}{|c|c|c|c|c|}
\hline 1. I wanted to use the goggles for longer. & $\begin{array}{l}\text { YES } \\
2\end{array}$ & / & $\begin{array}{c}\text { MAYBE } \\
1\end{array}$ & $\begin{array}{r}\mathrm{NO} \\
0\end{array}$ \\
\hline $\begin{array}{l}\text { 2. When you removed the goggles, did you } \\
\text { feel strange or weird? }\end{array}$ & $\begin{array}{l}\text { YES } \\
0\end{array}$ & / & $\begin{array}{l}\text { MAYBE } \\
1\end{array}$ & $\begin{array}{r}\mathrm{NO} \\
2\end{array}$ \\
\hline $\begin{array}{l}\text { 3. When you removed the goggles, did you } \\
\text { feel like you returned from a different } \\
\text { place? }\end{array}$ & $\begin{array}{l}\text { YES } \\
2\end{array}$ & / & $\begin{array}{c}\text { MAYBE } \\
1\end{array}$ & $\begin{array}{r}\mathrm{NO} \\
0\end{array}$ \\
\hline $\begin{array}{l}\text { 4. The game looked real. (E.g., The trees, } \\
\text { the river, and the sounds make you feel } \\
\text { like you were in a real river.) }\end{array}$ & $\begin{array}{l}\text { YES } \\
2\end{array}$ & I & $\begin{array}{c}\text { MAYBE } \\
1\end{array}$ & $\begin{array}{r}\mathrm{NO} \\
0\end{array}$ \\
\hline $\begin{array}{l}\text { 5. When the goggles were on, I felt like I } \\
\text { was actually there. (E.g., I felt like I was } \\
\text { at a river.) }\end{array}$ & $\begin{array}{l}\text { YES } \\
2\end{array}$ & / & $\begin{array}{c}\text { MAYBE } \\
1\end{array}$ & $\begin{array}{r}\mathrm{NO} \\
0\end{array}$ \\
\hline $\begin{array}{l}\text { 6. While I was using the goggles, I was } \\
\text { paying attention only to what I was } \\
\text { seeing and forgot about the real world. }\end{array}$ & $\begin{array}{l}\text { YES } \\
2\end{array}$ & / & $\begin{array}{c}\text { MAYBE } \\
1\end{array}$ & $\begin{array}{r}\mathrm{NO} \\
0\end{array}$ \\
\hline $\begin{array}{l}\text { 7. Do the river and objects in the game } \\
\text { make you feel like you were in the } \\
\text { middle of the game? }\end{array}$ & $\begin{array}{l}\text { YES } \\
2\end{array}$ & / & $\begin{array}{c}\text { MAYBE } \\
1\end{array}$ & $\begin{array}{r}\mathrm{NO} \\
0\end{array}$ \\
\hline $\begin{array}{l}\text { 8. I felt like sounds were coming from } \\
\text { different directions/places/all around } \\
\text { me. }\end{array}$ & $\begin{array}{l}\text { YES } \\
2\end{array}$ & / & $\begin{array}{c}\text { MAYBE } \\
1\end{array}$ & $\begin{array}{r}\mathrm{NO} \\
0\end{array}$ \\
\hline $\begin{array}{l}\text { 9. I felt I could have touched things in the } \\
\text { game. (E.g., I felt I could have touched } \\
\text { the goat or the wolf, etc.) }\end{array}$ & $\begin{array}{l}\text { YES } \\
2\end{array}$ & / & $\begin{array}{c}\text { MAYBE } \\
1\end{array}$ & $\begin{array}{r}\mathrm{NO} \\
0\end{array}$ \\
\hline
\end{tabular}

Total score: 


\section{Appendix B}

Enjoyment and Engagement Questionnaire

Observational (Researcher use)

- Does the child enjoy the experience? Yes/No Why?

- Does the child give up before finding the answer to the problem? Yes/No After attempts.

- Do you think the child was involved in the game (e.g., Paying attention, was persistent to find the answer)? Yes/No

Why?

Child questionnaire

The experimenter reads the questions to the child:

1. Would you like to play more games like this one?

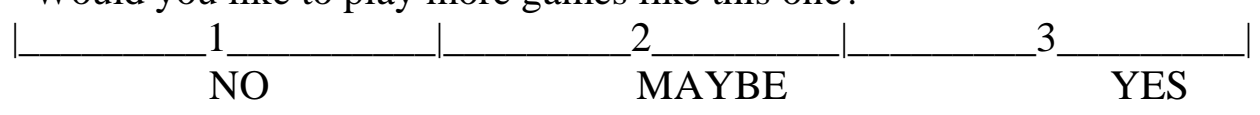

2. Would you like to show this game to your friends, brothers/sisters?

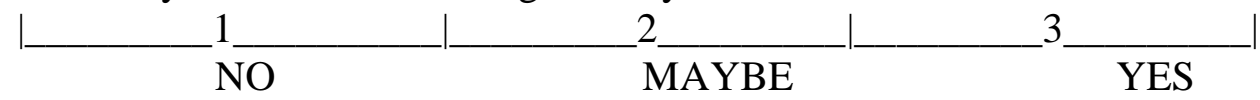

3. Did you worry about making mistakes while you were playing the game?

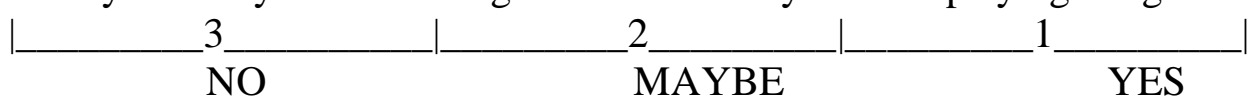

If Yes, when? (please give an example)

Note: Please do not ask the following question until the participant has completed the transfer-of-learning phase.

4. Would you prefer to play this game on the tablet, physical game or to play it with the goggles? (Note for researcher: Ask this question at the end of whole session).

Goggles Tablet $\quad$ Physical game 